\title{
A Contrasting Dark Background for Nail Sampling
}

\author{
Nina Blank, MD; Shari R. Lipner, MD, PhD
}

Accurate testing for onychomycosis requires procurement of ample subungal debris, which can be difficult to visually quantify. Specimen collection on a dark background-a black sticky note pad, for exampleto contrast with light-colored nail debris can help ensure an adequate specimen for fungal culture or polymerase chain reaction.

Cutis. 2021;108:341

\section{Practice Gap}

Mycologic testing is necessary and cost-effective ${ }^{1}$ for appropriate diagnosis and treatment of onychomycosis. Empiric treatment of onychodystrophy for presumed onychomycosis can result in misdiagnosis, treatment failure, or potential adverse effects caused by medications. ${ }^{2}$ Collection of ample subungual debris facilitates the sensitivity and specificity of fungal culture and fungal polymerase chain reaction. However, the naturally pale hue of subungual debris makes specimen estimation challenging, particularly when using a similarly light-colored gauze or piece of paper for collection (Figure, A).

\section{The Technique}

A sheet from a black sticky notepad (widely available and cost-effective) can be adapted for making a diagnosis of onychomycosis (Figure, B).

\section{Practical Implication}

Use of a dark background that contrasts with light-hued nail debris is valuable to ensure an adequate specimen for fungal culture and polymerase chain reaction.

\section{REFERENCES}

1. Gupta AK, Versteeg SG, Shear NH. Confirmatory testing prior to initiating onychomycosis therapy is cost effective. J Cutan Med Surg. 2018;22:129-141. doi:10.1177/1203475417733461

2. Lipner SR, Scher RK. Onychomycosis - a small step for quality of care. Curr Med Res Opin. 2016;32:865-867. doi:10.1185/03007995.2016.1147026
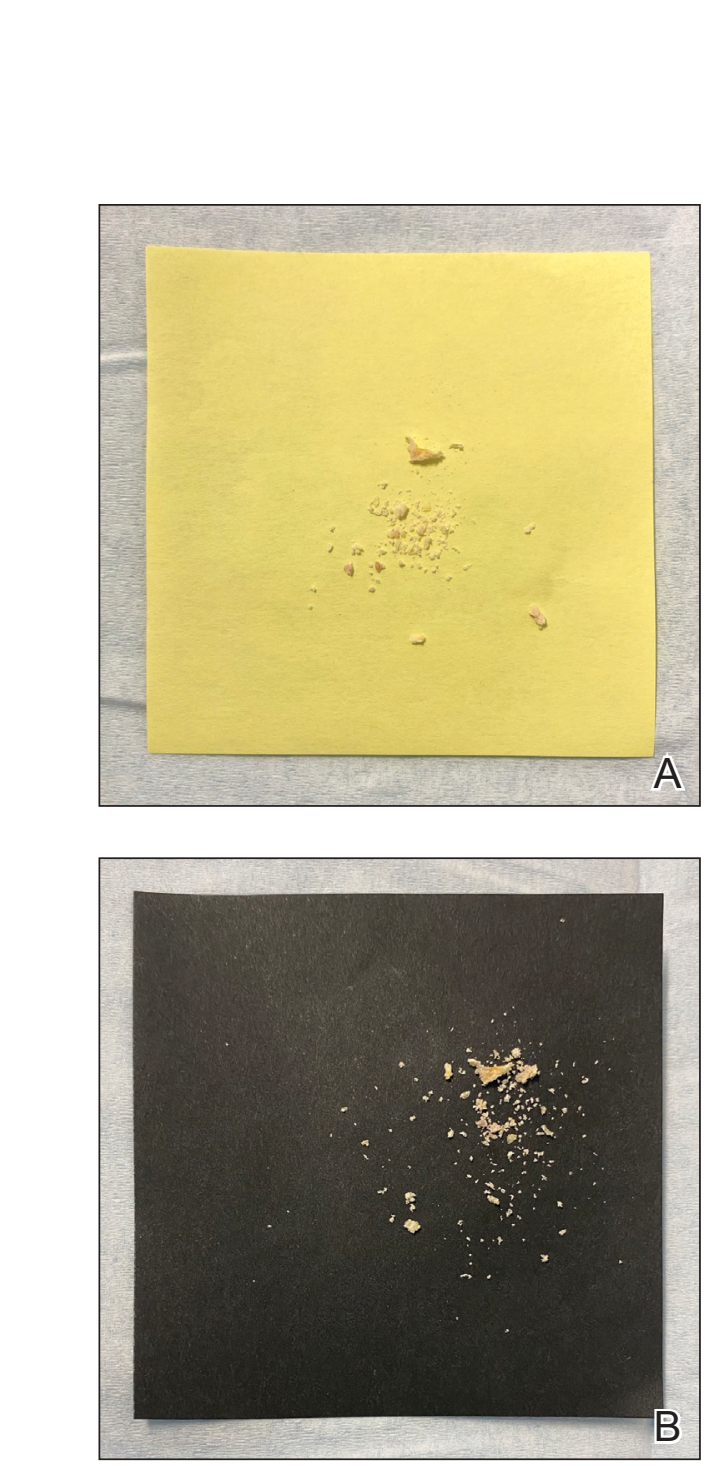

A, Nail debris collected on a yellow sticky note. B, The same nail debris was transferred to a black sticky note.

From the Department of Dermatology, Weill Cornell Medicine, New York, New York. 